\title{
Competencies in rheumatology: a European framework
}

\author{
Karen Lisbeth Faarvang, MD, European Board of Rheumatology \\ 1995-2008 ${ }^{\mathrm{a}, *}$, José Antonio da Silva, MD, PhD, Professor, President, \\ European Board of Rheumatology 2006-2010 ${ }^{\mathrm{b}}$
}

\footnotetext{
${ }^{a}$ Department of Rheumatology, University Hospital of Copenhagen, Gentofte, Niels Andersensvej 65, 2900 Gentofte, Denmark

${ }^{\mathrm{b}}$ Department of Rheumatology, University of Coimbra, Portugal
}

Keywords:

competency-based curriculum

curriculum development

curriculum planning

European rheumatology curriculum

harmonization

rheumatology curriculum framework

rheumatology training

specialist training

\begin{abstract}
The aims, structure, methods and educational experiences employed in the training of rheumatologists vary from one national programme to another, according to traditions, rules and resources. Mutual recognition of titles, the free movement of labour and the striving towards for high-quality standards in medical care in Europe demand that efforts and progress are made to ensure that similar competencies are achieved by different programmes. The European Rheumatology Curriculum Framework, developed by the European Board of Rheumatology, is meant to be a step towards the harmonization of rheumatology specialist training within the European Union, by providing a reference framework to the development and benchmarking of national curricula for the specialist training of rheumatologists. The European Rheumatology Curriculum Framework has now been endorsed by scientific and educational bodies in 17 member countries. It has been provided with a contextualized review of good practice in curriculum planning and development - the European Board of Rheumatology Educational Guide.
\end{abstract}

(ㄷ) 2008 Elsevier Ltd. All rights reserved.

The European Board of Rheumatology-UEMS (Union Européenne des Médecins Spécialistes) Section of Rheumatology developed and in 2008 presented, the European Rheumatology Curriculum Framework [1]. This is envisaged as a step towards the harmonization of rheumatology specialist training within the European Union (EU), by providing a reference framework to the development and benchmarking of national curricula for the specialist training of rheumatologists. It represents a major revision of the UEMS Rheumatology Specialist Core Curriculum produced in 2003.

\footnotetext{
* Corresponding author.

E-mail address: klfa@geh.regionh.dk (K.L. Faarvang).
} 
Here, we present a summary overview of the development, aims and contents of this document.

\section{Do we need a European rheumatology curriculum framework?}

In Directive 93/16/EEC of April 1993, the EU has specified that Member States shall ensure that the training leading to a diploma, certificate or other evidence of formal qualifications in specialized medicine meets a number of minimum quality criteria, including duration, content, setting and quality control. No guidelines for the specific content of the training are given. The conditions and regulations under which medicine and rheumatology are practised are extremely variable between different countries, and will remain so. Despite the closer relationships and increasing centralized regulations within the EU, definition of medical curriculum aims, structure and contents remain under the exclusive domain of national authorities.

The harmonization of specialist training in the EU is deemed essential to guarantee similar standards of care and support freedom of movement of medical specialists among member countries in the EU. This requires that both the public and the authorities are reassured that medical specialists coming from different countries hold similar competencies. Furthermore, international discussions around the aims and methods of training are an extremely useful means of highlighting deficiencies in local programmes and of fostering the dissemination of good practice. Guidelines on specialist training provide an important opportunity to increase quality standards on behalf of people with musculoskeletal conditions.

The European Board of Rheumatology holds neither the intent nor the authority to impose a defined curriculum structure, contents or aims to individual countries. The European Rheumatology Curriculum Framework aims solely at providing national authorities and professional bodies involved in the development of curricula for the training of rheumatologists with a comprehensive reference framework of core competencies to be achieved by the end of rheumatology training in the EU. Trainees can use it as a source of reference and benchmarking, for appreciation of their own training standards and source of inspiration to promote positive change where appropriate.

\section{Development process}

The European Board of Rheumatology-UEMS Section of Rheumatology is the representative body of rheumatologists within UEMS. Members of the European Board of Rheumatology are appointed by the appropriate professional and scientific national organizations of the speciality in the EU and European Free Trade Association (EFTA) countries in accordance with UEMS rules of procedure. Several countries outside EU and EFTA have associated members and observers in the European Board of Rheumatology. Each member country has two representatives.

One of the statutory purposes for The European Board of Rheumatology is the formulation of a common policy in the field of training aiming at the highest standards of rheumatology medical care in Europe.

Appropriate literature and other sources of information were consulted to synthesize the elements of best educational practice in the scope of this curriculum framework. Based on this work, the Board selected four major documents as the key sources of guiding principles and concepts:

1. The CanMeds Competency Framework [2].

2. The North American framework [3].

3. The British Specialty Training Curriculum for Rheumatology [4].

4. The Danish Curriculum for Rheumatology [5].

A working group was formed within the European Board of Rheumatology to write a first draft of the Curriculum Framework. This included the active participation of a delegate from the Permanent Working Group of Junior Physicians of the EU. Expert educational support was provided by Professor Reg Dennick, Assistant Director of the Medical Education Department of the University of Nottingham, UK. 
The draft was circulated for several rounds of remote and live discussion among the Board members and the national professional bodies. Corrections were made in accordance with the comments. The final version, approved on 31 January 2008, has now received endorsement by professional and educational authorities from 17 member countries of the UEMS (Fig. 1) as well as from the Permanent Working Group of European Junior Doctors.

\section{General structure and educational philosophy}

Many educational strategies can be adopted successfully for a curriculum in rheumatology. The strategy choice will largely depend on national traditions and resources. On this basis, the Board decided not to provide a formally structured curriculum but rather a framework of competencies to be achieved and assessed. National authorities will have to make a large number of decisions on the specifics of curriculum delivery and evaluation, in order to produce a curriculum plan that is clear, practical, comprehensive and usable by all parts involved.

To promote harmonization and quality, the European Rheumatology Curriculum Framework is provided with a contextualized review of good practice in curriculum planning and development. This has been compiled into a resource document addressing the qualities and limitations of different teaching, learning and assessment methods - the European Board of Rheumatology Educational Guide [6].

Another document - the UEMS Charter on the Training of Rheumatologists in Europe [7] - describes the general requirements for institutions, programmes and supervisors dedicated to the training of rheumatologists in any Member State of the EU. This establishes, among other aspects, the duration of training, the need for quality control and personal coaching, and well the requirement for recognition of training institutions and teachers. The role of trainees as the core drivers of their own education is stressed.

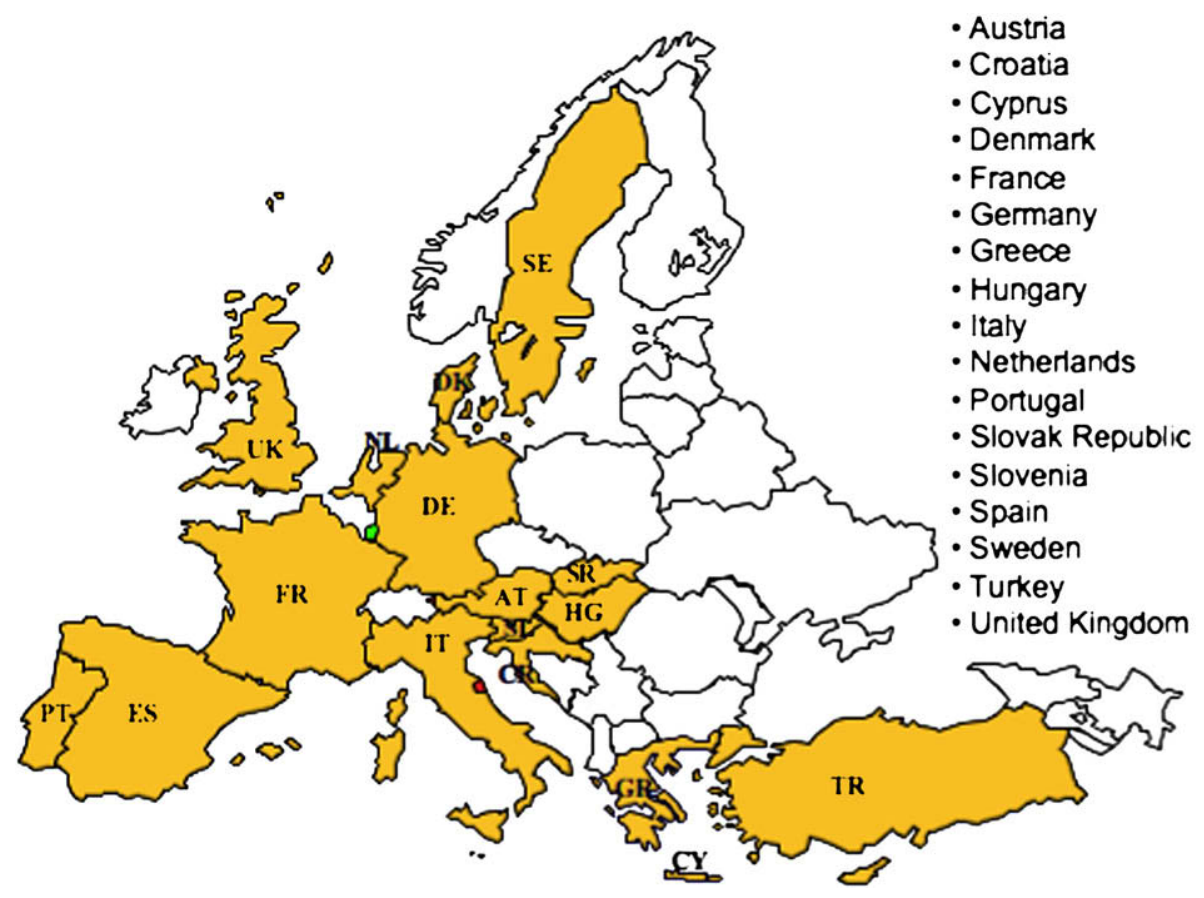

Fig. 1. Endorsement of the European Rheumatology Curriculum Framework, as of October 2008. AT, Austria; CR, Croatia; CY, Cyprus; DE, Germany; DK, Denmark; ES, Spain; FR, France; GR, Greece; HG, Hungary; IT, Italy; NL, Netherlands; PT, Portugal; SE, Sweden; SL, Slovenia; SR, Slovak Republic; TR, Turkey; UK, United Kingdom. 
The Curriculum Framework adopts an outcome-based approach[8], moving away from the definition of objectives in terms of knowledge and skills to a definition based around competencies. Competencies are defined as the ability to use knowledge, skills and appropriate attitudes and personal qualities to solve clinical problems in a professional, ethical and proficient way for optimal patient and societal outcomes [9,10].

Competency-based curricula have become, to a large extent, the standard in postgraduate education. However, it is essential that competencies are not treated in a narrow, behaviouristic way but that it is recognized that clinical skills are used as complex, holistic approaches embedded with professional values [11]. The curricula from North America [3], the UK [4] and Denmark [5] are also competencybased curricula.

The Board decided to organize the competencies in agreement with the CanMeds Seven Roles of Physicians (Box 1), as defined by the CanMeds Framework [2]. This was chosen in recognition of its ability to encompass the complex and ever-evolving roles the physician is expected to play in present day medicine. It underlines the need to bring crucial but previously ignored competencies, such as communication and professionalism, to the forefront of medical training objectives. Such competencies need to be fully recognized as central to the medical profession and can no longer be left to unchecked individual determination.

Certainly, the role of Medical Expert will continue to deserve a central place in medical education and training, but also the other six CanMed roles - Communicator, Collaborator, Manager, Health Advocate, Scholar and Professional - should be clearly represented in educational programmes.

The European Rheumatology Curriculum Framework has a section for each of the seven roles. Each section starts with a short definition of the role presented and a more extensive description of its nature in the perspective of the rheumatologist. This is followed by a list of key elements, which are meant to raise to consideration the diverse variety of dimensions that may be considered within that specific role. Key competencies deemed necessary for accomplishing the role are described at the levels expected by the end of training and this is followed by a more detailed description of specific training requirements within these competencies. Suggestions on appropriate teaching and learning as well as assessment methods for each of the competencies are presented (Table 1). In-depth description of these methods can be found in the European Board of Rheumatology Educational Guide [6]. A reference list for additional details and resources is given for each role. At the end of the framework, a list of conditions is added to clarify the clinical scope to be addressed by national curricula.

Describing the seven roles from the perspective of the rheumatologist is a never-ending challenge. In particular, the Board acknowledges the difficulties involved in defining the minimum competencies that a European Rheumatologist shall demonstrate by the end of the specialist training. Although this may be central for exams and accreditation processes, there is no critic-proof answer to the task of defining precisely a complex and flexible competence at a given moment within a continuum of professional development. Common sense and peer discussion will always have a major say in this area.

The authors believe, however, that the European Framework makes an important contribution in defending trainees and the curriculum from excessive detail and subspecialization in establishing that, at the end of training, trainees should only be asked to demonstrate 'operational knowledge':

\section{Box 1 The seven roles of the practicing physician, following the CanMeds framework}

- Medical expert

- Communicator

- Collaborator

- Manager

- Health advocate

- Scholar

- Professional 
Table 1

Structure of the European Rheumatology Curriculum Framework.

\begin{tabular}{ll}
\hline Structure of a section & Content \\
\hline $\begin{array}{l}\text { Definition } \\
\text { Description }\end{array}$ & $\begin{array}{l}\text { A short definition of the role } \\
\text { The nature of the role in the perspective of the } \\
\text { Rheumatologist }\end{array}$ \\
$\begin{array}{ll}\text { Elements } & \text { A list of the key elements for the specific role } \\
\text { Com competencies } & \text { accomplishing the role by the end of the training } \\
\text { Apecific training requirements } & \text { A description of training requirements within } \\
\text { the competencies }\end{array}$ \\
$\begin{array}{l}\text { Seaching and learning } \\
\text { Assessment methods }\end{array}$ & Assessment methods for each competencies presented \\
\hline
\end{tabular}

information at the depth needed for the skilful performance of all listed competencies, in the perspective of the practising rheumatologist in their national setting.

\section{The seven roles of the rheumatologist}

The medical expert

\section{Definition}

As Medical Experts, rheumatologists integrate all of the roles and competencies listed in the European Rheumatology Curriculum Framework, applying medical knowledge, clinical skills, and professional attitudes in their provision of patient-centred care. Medical Expert is the central physician role in rheumatology practice.

\section{Description}

Rheumatologists possess a defined body of knowledge, clinical skills, procedural skills and professional attitudes, which are directed to effective care of patients with rheumatic conditions. Their care is characterized by up-to-date, ethical, and resource efficient clinical practice as well as by effective communication in partnership with patients, other health care providers and the community. The role of Medical Expert is central to the function of rheumatologists and draws on the competencies included in the roles of Communicator, Collaborator, Manager, Health Advocate, Scholar and Professional.

\section{Elements}

- Core medical knowledge.

- In-depth knowledge of musculoskeletal problems and conditions.

- Medical history and examination.

- Diagnostic reasoning.

- Clinical judgement.

- Clinical decision-making.

- Risk-benefit and pharmaco-economic consideration.

- Assessment of the impact of musculoskeletal conditions.

- Application of appropriate management.

- Procedural skill proficiency.

- Team leadership.

- Evidence-based practice.

- Empathic care.

- Integration of all competencies to achieve optimal patient care.

- Application of ethical principles for patient care. 
Key competencies

By the end of training, a rheumatologist must be able to:

- Demonstrate diagnostic, management and therapeutic skills for ethical and cost-effective patient care in the complete array of musculoskeletal and connective tissue problems and conditions.

- Work in a multiprofessional and multidisciplinary team, recognizing the limits of his or her own expertise.

- Access, appraise and apply information that is relevant to clinical practice.

- Provide efficient support to the development of services related to disease prevention, patient care, patient and family education, social support, medical education and legal opinions.

With these points, the document aims to stress the importance of competencies of communication and cooperation, critical appraisal of evidence, cost consideration and advocacy even while considering solely the medical expert.

Specific training requirements

Training requirements for this role involve knowledge and clinical skills.

Knowledge. The knowledge basis, defined as 'operational', is organized around general knowledge (from basic statistics to legal regulations), basic sciences, clinical sciences (adult and paediatric conditions) and therapeutics. Readers interested in the details of this section are advised to consult the original document.

The Board refrained from being too specific about the exact content of knowledge in each of the areas or disciplines. Some documents of a similar nature, like the Core Curriculum Outline for Rheumatology Fellowship Programs in the USA [3], adopted a different strategy by listing down the immunological pathways and interactions that should be considered. The European Board felt that such a list can never be complete and could not be flexible enough to encompass the healthy cultural variability throughout Europe.

On the other hand, it was decided to underline the practical focus of the goals, stressing the ability to critically appraise and use knowledge in the resolution of clinical problems. For example, the need to master basic statistical and immunological concepts together with the importance of considering cost is highlighted, but the highest priority is given to reasoning skills and to the holistic approach of patients and their problems.

The document takes into consideration the variability among nations on who takes responsibility for paediatric rheumatic patients, suggesting different levels of performance according to the regulatory setting and the medical condition considered.

With regard to therapeutics, a comprehensive approach was adopted, which incorporated not only pharmacological agents abut also surgery, rehabilitation techniques, alternative medicines, multidisciplinary care and consideration of the psychosocial aspects of rheumatic diseases.

Clinical skills and practice. The core clinical skills required from the new rheumatologist include the ability to collect and interpret relevant information about a person with a musculoskeletal problem (history, physical examination, laboratory and imaging studies). The rheumatologist should be able to use this information in the light of medical knowledge to perform differential diagnosis, assess the patient's global status, plan further evaluation, and organize and implement a comprehensive management plan for the patient and assess its effect. This may include children, depending on the circumstances of practice at a national level. These skills are further defined to considerable detail.

Some technical skills are considered obligatory. These include: (1) aspiration of joints and bursae; (2) injection of joints and soft tissue; (3) synovial fluid analysis under polarized light; and (4) interpretation of musculoskeletal imaging, bone scintigraphy and bone densitometry.

With regard to the diversity of rheumatology practice in different European countries, some technical skills are considered optional and left for decision at a national level. In some countries, for example, rheumatologists perform arthroscopy; in other countries they do not. Paediatric rheumatology is a separate speciality in some but not in all European countries. Optional skills include, among others, biopsies of different tissues and organs, musculoskeletal ultrasound, capillaroscopy and arthroscopy. 
Teaching and learning methods

The document provides a list of recommended methods for teaching, learning and assessing the different competencies within each role. Following the guiding philosophy of the document, it is understood that the fine decisions regarding each method will be made at a national or local level. To foster sensible decisions, each of these methods is the object of a short description and appraisal in a rheumatological perspective, together with extensive referencing in the associated Educational Guide. The list pertaining to the Medical Expert role is presented here as an example.

Knowledge. Methods and resources for acquiring the recommended body of knowledge include, but are not limited to:

- Independent reading: recommended textbooks, journal articles and internet based research and study:

- Didactic teaching: conferences, lectures or discussions.

- Clinical laboratory experience.

- Dedicated courses.

- Clinical rounds.

- Involvement in teaching.

- Critical review of literature: journal clubs, etc.

Clinical skills and practice. Active involvement in patient care, in both the outpatient clinic and inpatient (hospitalized) settings, is the central pillar of skills acquisition. Such experiences must be duly supervised so that the trainee has abundant opportunity to observe skilled clinician role models, participate in the management of rheumatologic problems and receive appropriate, constructive feedback. Situations in which facets of patient care are taught and learned include:

- Didactic teaching: conferences, lectures or discussions.

- Clinical experience in a supervised, mentored clinical setting.

- Interactive case-based discussions.

- Independent reading: recommended textbooks, journal articles and internet-based research and study.

- Preparation of patient care portfolios.

- Clinical case presentations.

- Web-based case reviews.

Assessment methods

Knowledge

- Faculty performance rating: with regard to medical knowledge.

- Evaluation committee.

- Formal oral or written exam.

- Mentor evaluation of trainee's clinical performance.

\section{Clinical skills and practice}

- Regular formative appraisal and feedback.

- Faculty performance rating, with regard to patient care.

- Evaluation committee.

- Chart review: for patient care, drug prescribing, or outcomes.

- Presentations to peers and lay audiences. 
- Participation in individual or group quality improvement projects.

- Formal practical exam.

- Clinical evaluation exercise (mini-CEX).

- Direct observation of practical skills (DOPS).

- Objective structured clinical examination (OSCE).

- $360^{\circ}$ evaluations.

- Portfolio review.

\section{Communicator}

The ability to communicate effectively, not only with patients and their families but also with the general public, the authorities and colleagues, is core to the modern practice of medicine and rheumatology. It should, therefore, be formally represented in every training programme through explicit dedicated aims as well as recommended methods of teaching, learning and assessment.

\section{Definition}

As Communicators, rheumatologists effectively facilitate the doctor-patient relationship and the dynamic exchanges that occur throughout the course and medical management of what are frequently long-term conditions.

\section{Description}

Rheumatologists enable and nurture patient-centred therapeutic communication through shared decision-making and effective dynamic interactions with patients, families, caregivers, other professionals, and important other individuals. The competencies of this role are essential for establishing rapport and trust, formulating a diagnosis, delivering information, striving for mutual understanding, and facilitating a shared plan of care. Confidentiality and ethics must be respected.

The application of these communication competencies and the nature of the doctor-patient relationship vary for different cultures, conditions and individual needs for information. The potential barriers of language and culture need to be recognized.

\section{Elements}

- Patient-centred approach.

- Empathy, concordance, mutual understanding.

- Relational competence in interactions.

- Effective listening.

- Use of expert verbal and non-verbal communication.

- Respect for diversity.

- Interactive process.

- Eliciting and synthesizing information for patient care.

- Attention to the psychosocial aspects of illness.

- Conveying effective oral and written information for patient care.

- Shared decision making.

- Rapport, trust and ethics in the doctor-patient relationship.

- Constructive relationships with patients, families and caregivers.

- Capacity for compassion, trustworthiness, integrity.

- Flexibility in application of skills.

- Efficiency, accuracy.

- Breaking bad news.

- Addressing end-of-life issues.

- Disclosure of error or adverse event.

- Informed consent.

- Capacity assessment. 
- Appropriate documentation.

- Public and media communication, where appropriate.

Key competencies

By the end of training, a rheumatologist must be able to:

- Develop a good interaction with empathy, trust and ethical therapeutic relationships with patients, carers and families.

- Accurately elicit, select, document and synthesize relevant information and perspectives of patients and families, colleagues and other professionals.

- Adequately and understandably convey relevant information and explanations to patients and families, colleagues and other professionals.

- Propose and negotiate a common understanding on issues, problems and plans with patients and families, colleagues and other professionals to develop a shared plan of care.

- Convey accurate and effective oral and written information about a medical problem.

Specific training requirements

To acquire and demonstrate the competencies above, the trainee must exhibit, at the completion of training the following specific knowledge, skills and attitudes.

1. Develop a good interaction with empathy, trust and ethical therapeutic relationships with patients, carers and families:

1.1. Be a good communicator: rheumatologists must recognize that this is a core clinical skill for their practice and strive to master it. They should demonstrate an understanding that effective physician-patient communication can foster patient satisfaction, physician satisfaction, adherence and improved clinical outcomes.

1.2. Establish positive therapeutic relationships with patients and their families that are characterized by mutual understanding, trust, respect, honesty and empathy.

1.3. Respect patient confidentiality, privacy and autonomy.

1.4. Have good consultation skills and be able effectively to facilitate a structured clinical encounter by listening effectively, and being aware and responsive to non-verbal cues.

2. Accurately elicit, select, document and synthesize relevant information and perspectives of patients and families, colleagues and other professionals:

2.1. Gather information about the clinical condition, but also about a patient's beliefs, concerns, expectations and illness experience.

2.2. Select, appraise and document relevant information accurately and in a way that can communicate the information reliably to others.

2.3. Seek out and synthesize relevant information from other sources, such as a patient's family, caregivers and other professionals.

3. Adequately and understandably convey relevant information and explanations to patients and families, colleagues and other professionals:

3.1. Deliver information to a patient and family, colleagues and other professionals in a humane manner, recognizing their needs and in such a way that it is understandable, encourages discussion and participation in decision-making and concordance with a plan for management.

4. Propose and negotiate a common understanding on issues, problems and plans with patients and families, colleagues and other professionals to develop a shared plan of care:

4.1. Effectively identify and explore problems to be addressed from a patient encounter, including the patient's context, responses, concerns, and preferences.

4.2. Respect diversity and difference, including, but not limited to, the impact of gender, culture and religious beliefs on decision-making.

4.3. Encourage discussion, questions, and interaction in any encounters. 
4.4. Engage patients, families, and relevant health professionals in shared decision-making to develop a plan of care.

4.5. Effectively address challenging issues related to communicating with and supporting people with long term musculoskeletal conditions.

4.6. Effectively address challenging communication issues, such as obtaining informed consent, delivering bad news, and addressing anger, confusion and misunderstanding.

5. Convey accurate and effective oral and written information about a medical problem:

5.1. Maintain clear, accurate and appropriate records (e.g. written or electronic) of clinical encounters and plans.

5.2. Effectively present verbal reports of clinical encounters and plans.

5.3. Prepare reports for employers and agencies.

5.4. Understand the critical issues involved in presenting medical information to the public, to insurers or to the media about a medical issue.

Teaching and learning methods

Methods and resources that can contribute to the acquisition of these competencies include, but are not limited to:

- Experiential learning/tutorial learning: working with professionals who are examples of good practice and actively adopt a tutorial role towards the trainee in these domains is probably the most efficient way of promoting these competencies.

- Group case-based discussions.

- Role playing.

- Consultation under supervision/video followed by appraisal.

- Working with patient organizations and public groups.

- Patient partners.

\section{Assessment methods}

- Regular formative appraisal and feedback.

- Assessment of videotaped encounters.

- $360^{\circ}$ assessment.

- Clinical records review.

- Clinical reports review.

We have presented the central role (Medical Expert) and the Communicator role in some detail to give the reader a good perspective of the content and philosophy of the European Rheumatology Curriculum Framework. This does not preclude the need to consult the original document and associated publications for more detailed information.

For the sake of space and readability, the following roles will be presented in a more resumed format, highlighting only the most significant aspects.

\section{Collaborator}

Rheumatologists work in partnership with others who are appropriately involved in the care of individuals or specific groups of patients. Modern healthcare teams not only include a multidisciplinary group of professionals working closely together at one site, such as a ward team, but also extended teams with a variety of perspectives and skills, in multiple locations. It is therefore essential that rheumatologists are able to collaborate effectively with patients, families and an interprofessional team of expert health professionals for the provision of optimal care, education and scholarship.

Although collaborative attitudes and skills might be thought to develop spontaneously with training in the usual hospital setting, educational research shows that such competencies can be 
developed and trained to higher standards with dedicated programmes. Training programmes should, therefore, make sure that trainees and trainers are well aware and practice the key elements of this role. They include a culture of collaboration and mutual respect but also principles of team dynamics, multiprofessional healthcare, leadership and negotiation techniques, among others.

Competencies that should have been acquired by the end of training include the ability to:

- Participate effectively and appropriately in a multiprofessional and multidisciplinary healthcare team.

- Work effectively with other healthcare providers and agencies to negotiate and resolve issues relevant to patient care.

- Collaborate with organizations for people with musculoskeletal conditions.

Each of these competencies has been dissected into diverse aspects that deserve specific attention in a given training programme. The most important and effective way of developing such competencies consists of experiential learning within rheumatology departments, with professionals who are examples of good practice in these domains. There is no substitute for this and departments or individuals who do not qualify as good examples should probably not be accredited for teaching. Formal training can be provided through group case-based discussions and performance under supervision followed by appraisal or experiential learning with patient organizations and public groups.

Regular formative appraisal and feedback by competent supervisors is crucial. Trainers should be aware of these domains and identify problems and propose solutions. Other methods can be employed for formal assessment.

\section{Manager/medical leader}

Rheumatologists interact with their work environment as individuals, as members of teams or groups and as participants in the health system locally, regionally or nationally. They function as managers of practice activities involving a multidisciplinary team, resources and organizational tasks (such as care processes) and policies, as well as balancing their personal lives. Thus, rheumatologists require the ability to prioritize, to execute tasks collaboratively with colleagues and to develop the service while at the same time making systematic choices when allocating scarce healthcare resources.

Most physicians develop competencies in this area under traditional curricula. In most cases, this will happen later in life, when exposed to they are managing tasks. There is an increasing demand for the sensible use of such skills and there is little doubt that they will develop in a more sound, efficient and durable way if trainees and trainers keep them alive in their educational concerns and evaluations from the early phases of training.

The Board recommends that elements of organization, structure and financing of the healthcare system, career development, quality assurance and audit, leadership and aspects pertaining to managerial and leadership roles should be present in all programmes. These elements should be structured around competencies that are defined as clearly as possible in a way that is relevant to the actual training and practice environment. The recommend competencies are demonstrated by the ability to:

- Participate successfully in activities that contribute to the effectiveness of their healthcare organizations and systems.

- Manage their practice and career effectively.

- Understand and critically allocate finite healthcare resources appropriately in the interest of patients and the community.

- Serve in administration and leadership roles.

It is recognized that these competencies cannot be fully trained and acquired during specialist training, but will rather be develop and matured through continuing professional development. 
However, training programmes must set the basic conditions to facilitate this process and verify that they have been acquired at the appropriate level.

Again, the most important means of learning is by experiential learning in departments that can provide examples of good practice in these domains. Quality audit of training programmes should make sure that such conditions are present. Regular formative appraisal and feedback is the most relevant way of assessment but other instruments, such has reflective portfolios and $360^{\circ}$ evaluations can also be used for this purpose.

\section{Health advocate}

As Health Advocates, rheumatologists use their expertise and influence responsibly to advance the health and well-being of individual patients, communities and populations, especially with respect to musculoskeletal and connective-tissue conditions.

Rheumatologists must recognize and embrace their duty to promote the overall health of their patients and the society they serve. They need to recognize advocacy activities as important for the individual patient, for populations of patients and for communities. Individual patients need physicians to assist them in navigating the healthcare system and accessing the appropriate health resources in a timely manner. Communities and societies need rheumatologists' special expertise in identifying health risks and solutions with respect to the musculoskeletal system, as well as their contribution to wise and equitable allocation of health resources. At this level, health advocacy involves efforts to change specific practices or policies on behalf of those served. Health advocacy is appropriately expressed both by individual and collective actions of physicians in influencing public health and policy.

There would, we believe, be little argument about the importance of this role or also about the decisive impact of experiences during training in establishing such crucial aspects of the medical culture in any given physician.

Training programmes - through regulations, specific aims and activities and, above all, committed supervisors - should make sure that every trainee is made aware of issues surrounding advocacy for individual patients, populations and communities; of the individual and socioeconomic burdens of musculoskeletal diseases; of the structure and functioning of the health and social security systems; and of the responsible use of authority and influence.

The European Framework document recognizes that competencies cannot be fully acquired during fellowship but recommends that specific objectives and experiences are planned and appraised for this purpose in order to structure and foster the further future professional development of each individual. Recommended learning and assessment methods are similar to those suggested for the Manager role.

\section{Scholar}

As Scholars, rheumatologists should demonstrate a lifelong pursuit of mastering their domain of expertise and engage in the creation, dissemination, application and translation of medical knowledge of their field. They must recognize and assume their role as formal or informal teachers and educators (role models). Accordingly, they facilitate the education of their students, patients, colleagues, health professionals and community.

The training programme can have a decisive impact by rooting these principles and attitudes in the physician. The Board recommends that, as part of their professional education, at the completion of training rheumatologists must demonstrate the abilities and attitudes needed to:

- Enhance the quality of their professional performance through ongoing learning and selfassessment

- Apply the principles of evidence-based medicine in their practice.

- Facilitate the learning of patients, families, students, trainees, relevant health professionals, the public and others, as appropriate.

- Contribute to the development, dissemination, and translation of new knowledge and practices, especially in the field of rheumatology. 
- Exercise appropriate interaction with industry and other commercial interests, with due consideration of risks regarding conflicts of interest.

To achieve these requirements, the training programme must incorporate opportunities to exert and discuss key elements of scholarship, such as self-assessment, accountability, critical appraisal of practice and evidence, communication, evidence-based medicine.

Teachers and programme leaders must be critically aware of the importance of role modelling and mentoring in the development of such attitudes and values. Practical involvement in teaching, audit and appraisal, as well dedicated courses on these issues, are also recommended as methods of learning.

These competencies should be evaluated and accredited if they are to be acquired. Regular formative appraisal and feedback, together with the use of portfolios and $360^{\circ}$ assessments are the most adequate methods in the field.

\section{Professional}

Rheumatologists, like all physicians, have a unique role as professionals who are dedicated to the health and caring of others. Their work requires the mastery of a complex body of knowledge and skill, as well as the art of medicine. As such, the Professional role is guided by codes of ethics, a commitment to clinical competence, the embracing of appropriate attitudes and behaviours, integrity, altruism, personal wellbeing and the promotion of the public good within their domain. These commitments form the basis of a social contract between the physician and society. Society in return, grants physicians the privilege of profession-led regulation with the understanding that they are accountable to those served.

In short, as professionals, rheumatologists are committed to the health and well-being of individuals and society through ethical practice, profession-led regulation and high personal standards of behaviour.

Although these concepts are difficult to capture in short sentences and clear objectives, the Curriculum Framework recommends that all programmes should have specific goals, learning opportunities and evaluations on professionalism. They might need cultural adaptation from those stated in the document:

- Demonstrate a commitment to their patients, profession, and society through ethical practice.

- Demonstrate a commitment to their patients, profession and society through participation in profession-led regulation.

- Demonstrate a commitment to physician health and sustainable practice.

It is recognized that these competencies will develop and mature through continuing professional development. Training programmes must, however, establish the appropriate standards and reinforce the attitudes that will lead to lifelong commitment to the principles.

Experiential learning in rheumatology departments that are examples of good practice in these domains is the most efficient way of promoting these competencies. Sensible and dedicated mentoring is essential. Demonstration of excellence on this domain must be key to the department's accreditation for teaching.

The acquisition and sedimentation of professionalism can be further facilitated by faculty discussions on issues and exemplary cases, and can be combined with dedicated lectures and courses, among other methods.

Assessment can be based on a combination of portfolio review, appraisals and ratings of performance by peers, associated workers and patient surveys.

\section{How to use the framework}

The European Rheumatology Curriculum Framework is not a finalized curriculum but merely a guide. It aims to provide national authorities with inspiration and benchmarking, although different educational strategies can and will be adopted depending on traditions, rules and resources. Transforming the Framework into a formal, competency-based curriculum involves decisions on the optional skills and competencies, deciding on adaptations to national needs and describing how the training programme works to develop and assess the elected competencies. It should specify how 
the training and educational experiences are structured and aligned over time, and which methods are used to evaluate the development of competencies.

Even when a country has fully adopted the European Rheumatology Curriculum Framework, many decisions are needed to develop a national curriculum:

- Needs analyses.

- Curriculum structure, philosophy and values.

- Aims, outcome and competencies.

- Content.

- Learning systems and environments.

- Learner support and development.

- Assessment.

- Staff support and development.

- Management, evaluation and quality assurance.

- Methods of implementation.

Several resource documents can be added to the European Curriculum Framework to help develop national curricula. The European Board of Rheumatology Educational Guide[6] describes the basic principles of curriculum planning and management, teaching and learning methods and assessing methods, taking into account the specificities of rheumatology.

The American Core Curriculum Outline (March 2006) [3] is also a framework. It offers excellent examples of organization and nomenclature for a competency-based curriculum, as well as an important series of practical examples for specific clinical attachments.

The British (May 2007) [4] and the Danish (August 2007) [5] curricula are excellent examples of competency-based curricula and also offer good examples of curriculum maps, aligning objectives, with methods for learning and assessment.

Finally, the UEMS Charter on the Training of Medical Specialist in Europe [7], written in cooperation with the European Commission, outlines the general requirements and guidelines for adequate training. A section specifically devoted to each individual speciality designed by the respective sections completes the document. The UEMS Charter on Training of Rheumatologists [7] is produced by the European Board of Rheumatology. It specifies the requirements for adequate training to prepare specialists for practice in the speciality of rheumatology at an appropriate level in any Member State of the EU. This document was revised and approved in December 2006.

\section{Implementation}

To implement the European Curriculum Framework, it needs to be recognized and adopted at a national level. At present, the Curriculum is being circulated within national authorities and professional bodies in Europe for endorsement. This endorsement will mean that the organization: 'recognizes the value of the European curriculum framework as valuable guidance providing a framework toward harmonization of training and professional competence of rheumatologists within Europe and its individual countries. That they will use the document as inspiration in the design and delivery of national curricula and programmes related to the training of rheumatologist'. By October 2008, the most representative scientific and professional organizations from 17 European countries have signed the endorsement document.

The Curriculum Framework was presented at the EULAR Congress 2008 and members of the European Board of Rheumatology are encouraged to present it in national journals of rheumatology.

\section{Summary}

This chapter presents the new European Rheumatology Curriculum Framework, which has been produced by the European Board of Rheumatology. The Curriculum Framework has adopted the CanMeds [2] roles of Medical Expert, Communicator, Collaborator, Manager, Health Advocate, Scholar 
and Professional. It provides an extensive list of competencies in the different domains that European rheumatologists are expected to have archived by the end of their specialist training.

In a competency-based curriculum framework devoted to rheumatology, each of the seven roles is briefly defined, the nature of the role is described, competencies deemed to be key for the role are listed, specific training requirements are described and teaching, learning and assessments methods are suggested. This is meant as inspiration for the development of national curricula in rheumatology, because final decisions on the exact content and strategy of specific training programmes remain at a national level and will depend on local rules, traditions and resources.

The curriculum framework is supplemented with an Educational Guide, which is designed to help policy makers and teachers to better structure their curriculum development plans and to select among the numerous methods of teaching and assessment. These decisions can be assisted by the European Rheumatology Curriculum Framework and the European Board of Rheumatology Educational Guide to ensure a harmonization of rheumatologists training in Europe.

\section{References}

*[1] The European Rheumatology Curriculum Framework. Available from: http://www.uems-rheumatology.net.

*[2] Frank JR, editor. The CanMed 2005 Physician Competency framework. Better standards. Better physicians. Better care. Ottawa: The Royal College of Physicians and Surgeons of Canada; 2005.

*[3] American College of Rheumatology. Core curriculum outline for rheumatology fellowship programs. A competency-based guide to curriculum development. Available from: http://www.rheumatology.org/educ/training/CCO.pdf; March 2006.

*[4] Joint Royal Colleges of Physicians Training Board. Available from: http://www.uems-rheumatology.net; May 2007.

*[5] The Danish Curriculum for Rheumatology. Available from: http://www.uems-rheumatology.net.

*[6] The European Board of Rheumatology Educational Guide. Available from: http://www.uems-rheumatology.net.

*[7] da Silva JAP, Faarvang Karen L, Bandilla Klaus, Woolf Antony D, on behalf of the European Board of Rheumatology. UEMS charter on training of rheumatologists in Europe. Ann Rheum Dis 2008;67:555-8. Available from: http://www.uemsrheumatology.net.

*[8] AMEE Medical Education Guide no. 14: outcome-based education. Dundee: Center for Medical Education; 1999.

[9] Hager P, Gonezi A. What is competence? Med Teach 1996;18:15-8.

*[10] Epstein RM, Hundert EM. Defining and assessing professional competence. JAMA 2002;287:226-35.

*[11] Fish D, Coles C. Medical education: developing a curriculum for practice. Maidenhead: Open University Press; 2005.

\section{Further reading}

[1] ABIM medical professionalism in the new millenium: a physician charter. Ann Intern Med 2002;136:243-6.

[2] Advancing education in practice-based learning and improvement. An educational resource developed by the ACGME to aid program directors in teaching and assessing PBLI. Available from: http://www.acgme.org/outcome/implement/ complete_PBLIBooklet.pdf.

[3] Advancing education in professionalism. An educational resource developed by the ACGME to aid programme directors. Available from: http://www.acgme.org/outcome/implement/Profm_resource.pdf.

[4] American Medical Association. Embedding professionalism in medical education: assessment as a tool for implementation. Available from: http://www.nbme.org/PDF/NBME_AAMC_ProfessReport.pdf.

[5] Blank L. Medical professionalism in the new millennium; a physician charter 15 months later. Ann Intern Med 2003;138: 839-41.

[6] Branch W. Feedback and reflection: teaching methods for clinical settings. Acad Med 2002;77:1185-8.

[7] Burack JH, Irby DM, Carline JD, et al. Teaching compassion and respect. Attending physicians' responses to problematic behaviors. J Gen Intern Med 1999;14:49-55.

[8] Epstein RM. Mindful practice. JAMA 1999;282:833-9.

[9] Hatem CJ. Teaching approaches that reflect and promote professionalism. Acad Med 2003 Jul;78(7):709-13.

[10] Interpersonal and communication skills. An educational resource developed by the ACGME to aid programme directors in teaching and assessing interpersonal and communication skills. Available from: http://www.acgme.org/outcome/ implement/interperComSkills.pdf.

[11] Klein EJ, Jackson JC, Kratz L, et al. Teaching professionalism to residents. Acad Med 2003 Jan;78(1):26-34.

[12] Kuczewski M. Fostering professionalism: the Loyola model. Camb Q Healthc Ethics 2003;12:161-6.

[13] McCormick BB, Tomlinson G, Brill-Edwards P, Detsky AS. Related articles, effect of restricting contact between pharmaceutical company representatives and internal medicine residents on post-training attitudes and behavior. JAMA 2001 Oct 24-31;286(16):1994-9.

[14] Moore DE, Pennington FC. Practice-based learning and improvement. J Contin Educ Health Prof 2003;23:S73-80.

[15] NBME behaviors of professionalism. Available from: http://ci.nbme.org/professionalism.

[16] NBME embedding professionalism in medical education: assessment as a tool for implementation 2002. Available from: http://www.nbme.org/PDF/NBME_AAMC_ProfessReport.pdf.

[17] Rothman DJ. Medical professionalism - focusing on the real issues. N Engl J Med 2000;342:1284-6.

[18] Siegler M. Training doctors for professionalism: lessons learned from teaching clinical medical ethics. Mt Sinai J Med 2002;69:404-9. 
[19] Steinert Y, Cruess S, Cruess R, Snell L. Faculty development for teaching and evaluating professionalism: from programme design to curriculum change. Med Educ 2005 Feb;39(2):127-36.

[20] The ACGME also has a comprehensive list of professionalism references. Available from: http://www.acgme.org/ outcome/comp/refProf1.asp.

[21] The ACGME provides several assessment tools for the evaluation of professionalism. Available from: http://www.acgme. org/outcome/assess/proflndex.asp.

[22] The American Medical Association Ethics Publication 'Virtual Mentor'. Available from: http://www.virtualmentor.org. 